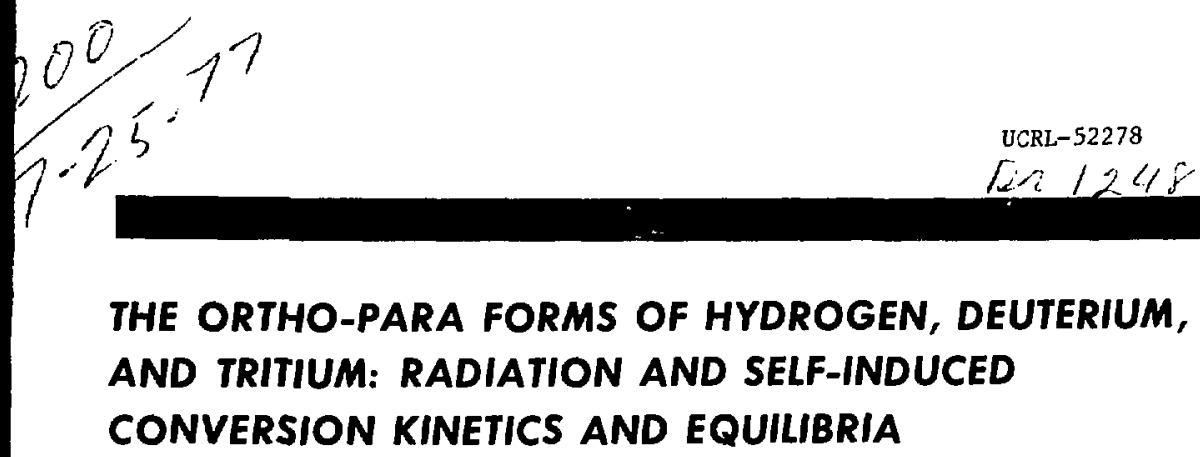
J. W. Pyper
C. K. Briggs

Mindieí

June 16, 1977

Prepared for U.S. Energy Research \& Development

Administration under contract No. W-7405-Eng-48

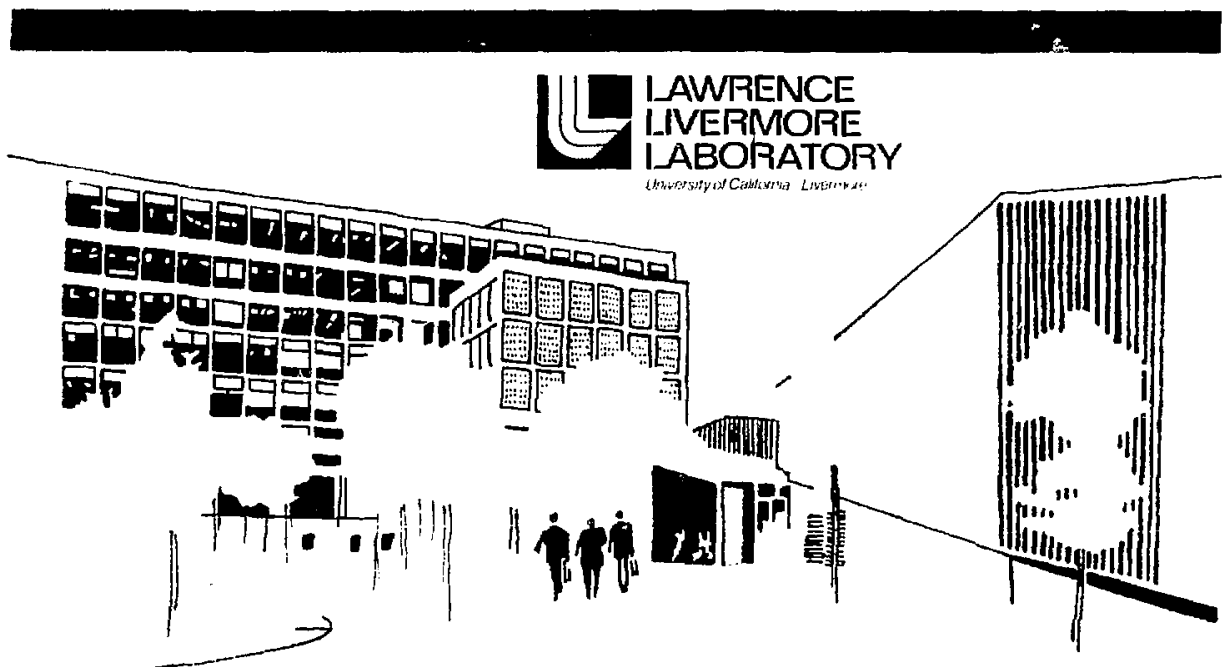




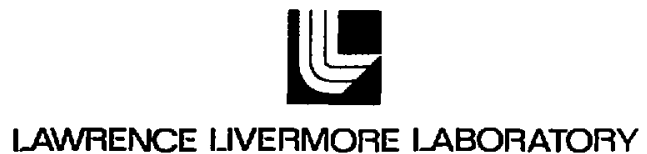

University of Cahfornia Livermore.California 94550

THE ORTHO-PARA FORMS OF HYDROGEN, DEUTERIUM, AND TRITIUM: RADIATION AND SELF-INDUCED CONVERSION KINETICS AND EQUILIBRIA

\author{
i.l. Pyper \\ C.R. Brighs
}

MS. date: June 16, 1977

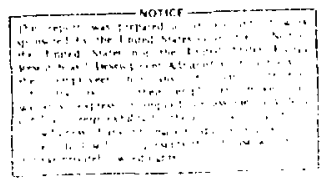




\section{Contents}

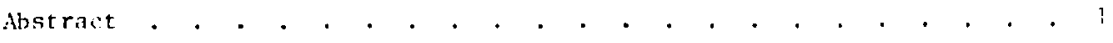

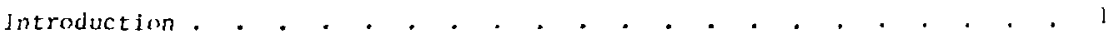

Theory uj Ortik-Para Transitions . . . . . . . . . . . . . . :

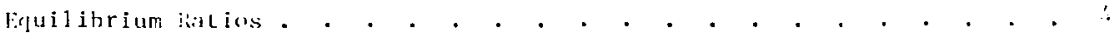

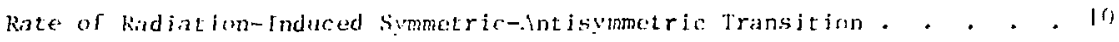

Seli-lnduce symelric-intisymetric Conversion kinetics . . . . . . I.

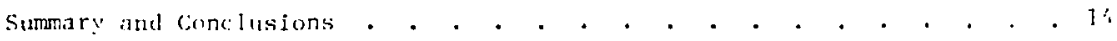

Acknovledgmunts. . . . . . . . . . . . . . . . . . . . l?

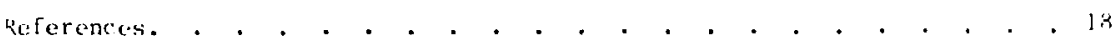




\title{
THE ORTHO-PARA FORM S OF HYDROGEN, DEUTERIUM, AND TRITIUM: RADIATION AND SELF-INDUCED CONVERSION KINETICS AND EQUILIBRIA
}

\author{
Abstract \\ The lacors is the ortiompara cran- \\ sit ions in $\mathrm{H}_{2}, \mathrm{I}_{2}$, and $\mathrm{T}$, iti \\ developed. Feperimental and anlen- \\ lated velues at the urtho-para cum- \\ pasilions of the three hydrogen \\ iseicepes mentioned in the Titeristure \\ aro rerrelated ats a function of tellit- \\ fereatere, and are discussed irit- \\ ally. like binel ies of lid. Mdia- \\ tion and ac! -induced artho-para \\ transilirme: are revieved. In

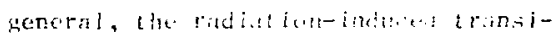 \\ tions are more rajid than the self-

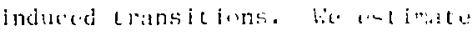

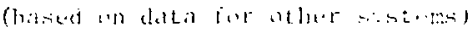

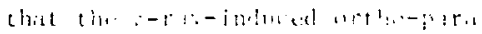

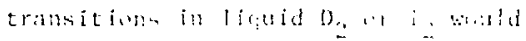

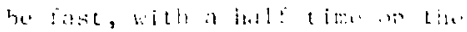

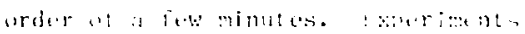

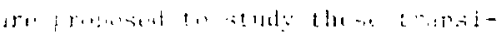

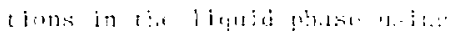

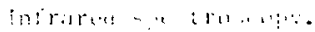

\section{Introduction}

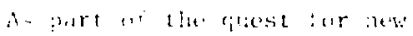

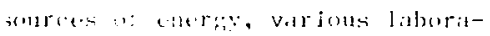
fories throughent the borld are troing

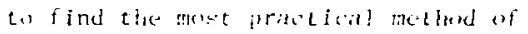

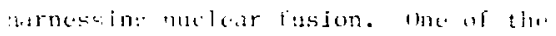

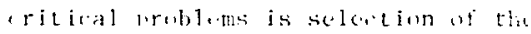

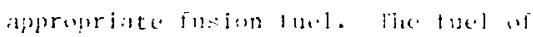

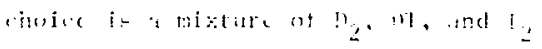
(hereater referred to is at) that

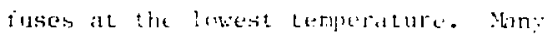

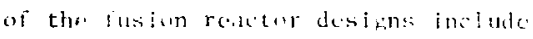

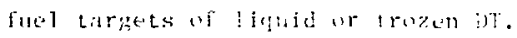
since there je ? ittle d.ata on $7-\cdot \cdot n-$ laining isucopir molerules ut hadruen at tempuratures near the triple point,
Wh have l.

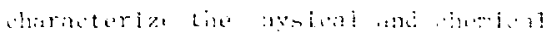

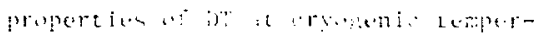

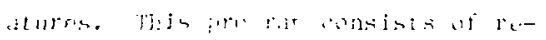

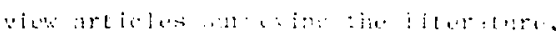

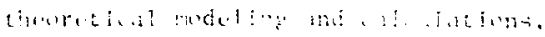

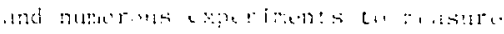

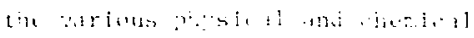

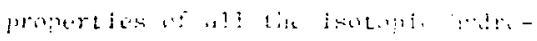

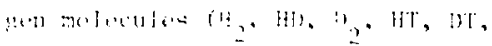

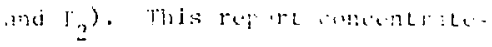

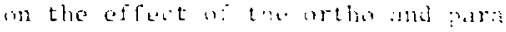

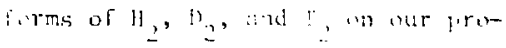

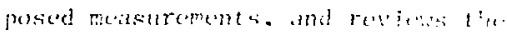

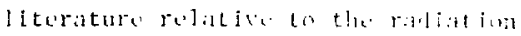


and self-induced ortho-para conversions in the homonuclear diatomic hydrogen molecules.

There is considerable 1 iterature on ortho-para conversion in hydrogen in the gas phase. This reaction has been especially attractive to physicists who desired tests of the postulates of quantum mechanics, and to chemists who used this system for studies of catalysis and kinetics. There are several helpful articles with extensive literature reviews to which we refer for general surveys of the field. An exhaustive review of the early literature (up to 1935) is provided hy Farkas. 1 Schmauch and Singleton $^{2}$ in 1964 gave a straightforward review of the various methods of catalysis of the ortho-para transition. Scalipino and Pelzinger ${ }^{3}$ furnish a recent (1974) mathematically rigorous review of surface catalysis by magnetic materials. Our review is necessarily limited by our interest in the radiation and self-induced processes.

\section{Theory of Ortho-Para Transitions}

The prediction of the ortho-para forms of homonuclear diatomic molecules (including $\mathrm{H}_{2}, \mathrm{D}_{2}$, and $\mathrm{T}_{2}$ ), and the subsequent experimental verification, was one of the early triumphs of quantum statistical mechanics. 4 The properties of the molecules that lead to the ortho-para forms are the nuclear spin of the nucleus and the rotation of the molecule. ${ }^{5} \wedge 11$ other properties such as translation, vibration, etc., are the same for the two forms. The combined nuclear spinrotational partition function ${ }^{6,7}$ is given by

$$
\begin{aligned}
z_{r=} & \sum_{J=0,1,2, \ldots g^{j}(2 J+1)} g \\
& \times e-\frac{J(J+1) \theta_{r}}{T}
\end{aligned}
$$

in the gas phase, where $g_{j}$ is the nuclear spin degeneracy, $J$ is the rotational quantum. number, and $T$ is the absolute temperature. In Eq. (1), $\theta_{r}$ is the so-called rotational temperature which is equal to $h c B / k T$, where $h$ is Planck's constant, $c$ is the speed of light, $k$ is Boltzmann's constant, and $B_{e}$ is the rotational constant which is different for eich isotopic molecule and is proportional to the moment of inertia.

According to the rules of the quantum theory, homonuclear diatomic molecules can exist in states with even $J$ or odd $\mathrm{J}$ but not both. Hence the two forms of hydrogen-one represented by an even series, the other by an odd series. $\Lambda$ ssociated with these two series are certain $g_{i}$ values, which 
are the same for $\mathrm{H}_{2}$ and $\mathrm{T}_{2}$ since they have the same nuclear syln, but are different for $D_{2}$ since its nuclear spin differs from the other two. The ortho-para properties for $\mathrm{H}_{2}, \mathrm{D}_{2}$, and $T_{2}$ are listed in Table 1.

vote that some confusion arisc's since the even (symmetric) series for $\mathrm{H}_{2}$ and $\mathrm{I}_{2}$ is called para, while the even aeries for $)_{2}$ is called wrthe. The name arthe wass applied to the species af $\mathrm{li}_{2}, \mathrm{D}_{2}$, or $\mathrm{T}_{2}$ thit were most abundant it room temperature. ${ }^{8}$ this designiation was applied before the currelation with rotational properties wits discovered; it persists unt i.l the fresont. The asse of the terms symnct$r i$, and antis:ouret $r i c$ can be used $l o$ - jirinatu this conlusion.

It hats been shown expertimentall!" that the two forms of $\mathrm{H}_{2}, \mathrm{I}_{2}$, ind $\mathrm{T}_{2}$ are quite stable and requirt some kind of catitytire procesis to convert from ane iorli to another. 1,2 There are two fundanental catalytic mechanisns that cause the svmet ric-intisymet $r$ ic transitions: (1) the chellical mechanism in whith the melecule it dissociated into atoms or inns and is allowed to recombine, and (2) tic linsical methanism in which the auclear ypin of the atoms inturats uth an inhom-

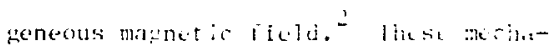
nisms will he discusted in tixe last sertion. At rom temperature, the ajuilibrium symeric-anlisymetri.

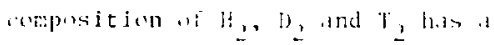

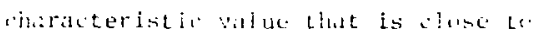
the high-temperature anjust inns shown in rable l. May symetricantisymetefle ris that has this aropesition is fonden as normal (i) ; at any other temperature, the equilithiumi mixture ot the formse in desianded an equilibrian (e). In the shomese ot is

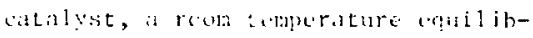

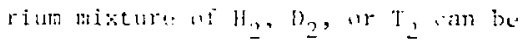

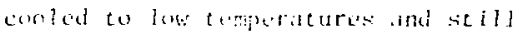
have a normat crmpenitinn. In tine ulier hand, the pure semanetric iorms

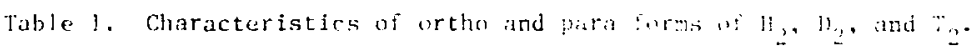

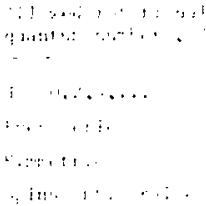


of $\mathrm{H}_{2}, \mathrm{D}_{2}$, and $\mathrm{T}_{2}$ can be prepared by cooling a normal mixture of the isotope to very low temperature in the presence of a catalyst, then removing the catalyst.

The symmetric-antisymmetric transition can be written in an analogous form to a chemical reaction. let $x_{2}$ be any of the hydrogen isotopic species $\mathrm{H}_{2}, \mathrm{D}_{2}$, or $\mathrm{T}_{2}$, Then the ortho-para transition can be written

$x_{2}$ (ODD SFRIES $) \approx x_{2}$ (EVEN SERTES).

In a fashion analogous to a chemical equilibrium constant, we can designate a composition ratio $R$ in the gas phase

$R\left(\mathrm{X}_{2}\right)=\frac{\left[\mathrm{X}_{2} \text { (EVEN SERIES) }\right]}{\left.\left[\mathrm{X}_{2} \text { (ODD SERIES }\right)\right]}$.

Using this formalism, Eq. (1), and the restrictions given in Table 1 , we can define the following relationships:

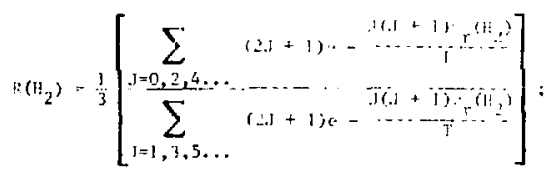

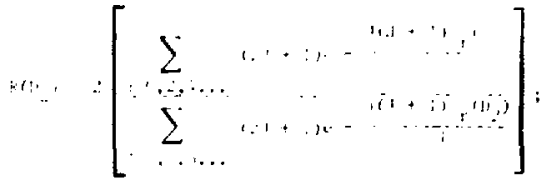

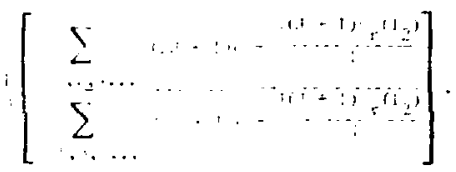

Note that the $s_{i}$ ractors have been removed from inside the summations, and cancellations have been as appropriate. It is a simple matter to alculate the $R\left(\mathrm{X}_{2}\right)$ values using ${ }^{\prime} r$ values rrom molecular spectroscopy. 9 This has been done by other workers for the gas phase; we will compare these results with experiment in the next section.

Usually in the literature, the compasitions of ortho and para species are given in terms of $\%$ artho or $\%$ para rather thas: $\mathrm{R}\left(\mathrm{X}_{2}\right)$ values. Jhe $:$ EVEN SHRISs is calculated by

\% (EVLN SERHLS)

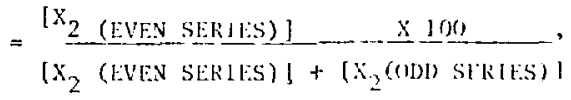

with an analogous expression for the \% (ODD SERTES).

\section{Equilibrium Ratios}

Giauque $^{10}$ was the first to calculate the symmetric-antisymmetric com- position of hydrogen using the method described in the preceding section. 
By the same method, Harkness and Deming ${ }^{11}$ extended the symmetricantisymmetric compositions of hydrofien to other temperatures.

In 1934, lohnston and Long ${ }^{12}$ perfurmed similar calculations for $\mathrm{D}_{2}$, and in 1948 Jones $^{13}$ did the same for $\mathrm{T}_{2}$. Mhers ct $\therefore{ }^{14}$ also report a table of ortho-para compositions for $\mathrm{T}_{2}$. In the context of their papers, Lhcse data could be mistaken for experimental values. Careful reading, hrwever, indicates they cannot be. These datia therefore must be results uf thouritical calculations, but no omrre is given for them nor details of che calculations. Because of the nne ertainty of source, we have omitted ture datal from our compilation. In 1945, Faurnfelder $\therefore i^{15}$ reported a corplete set wi the calculated wlues of the symmetric-antisymetric corposesitions of $\mathrm{H}_{2}, \mathrm{D}_{2}$, and $\mathrm{T}_{2}$ in the gas phase; and the measured symmetricant isymetric compositions desurbed from a cen 2 catislyet. Nll of the furceuing, resultes are sumiarized in Tiables ?-4. Table 2 compares the calculated and criperimental values of che percentape if the even sories (svimetric form) and the (ailculated and experimental vialues of $R\left(X_{2}\right)$ for hydrogen. be have included all the dita from Giauque, 10 al1 the datia of Ret. 15 (calculated and experimental) and the data of Harknesti and Demingr 11 at certain temperatures. Only part of the data frosa liurtaness and boming whs retained because we wanted to keep the table smaller and to include all the more recent data of kef. 15. Table 3 makes the same comparison as just 1 isted in Table 2, but for all the data we lound for deuterium. Table 4 alsu makes the sane comparison as Tables 2 and ' , but includes all the data we found fur tritium with the exception of Ref. 14 whith we discussed previnuly. In Fig. 1, all the aven-seriosiforms for the three isotopes of hydrogen ate plinted versis the absolute temperaturis. As is evitiont, the exarimental maturemeats and the wirulated poringages

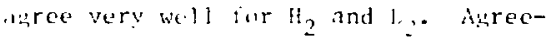
ment between the alsolaled and meatsuret percentestes is nut as gond for $\mathrm{T}_{2}$. The autiars at thibute this disigrement on tike effect if the tritiur, -ray witish caldses lually high tomperatures aling its path, thereby witting the sumetricant is vmatrio percentages thward the his!l-tamerattate viltes. Error is

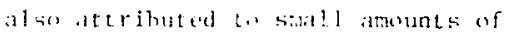
Ht and br in the $i$, smales. Sues alsu tilat the liaro values of $\mathrm{R}\left(\mathrm{X}_{2}\right)$ are not andrate the reasun is that an acruratel: kandin lirse number is

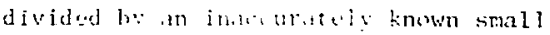
number. Fir jurmene of extrapolat ins

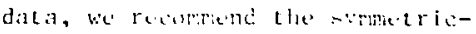

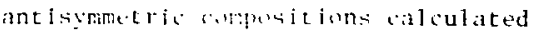
by Frauenfolder . . 15 inr all three 
Table 2. Percentage symetric forms and $\mathrm{R}\left(\mathrm{H}_{2}\right)$ values for bydrogen.

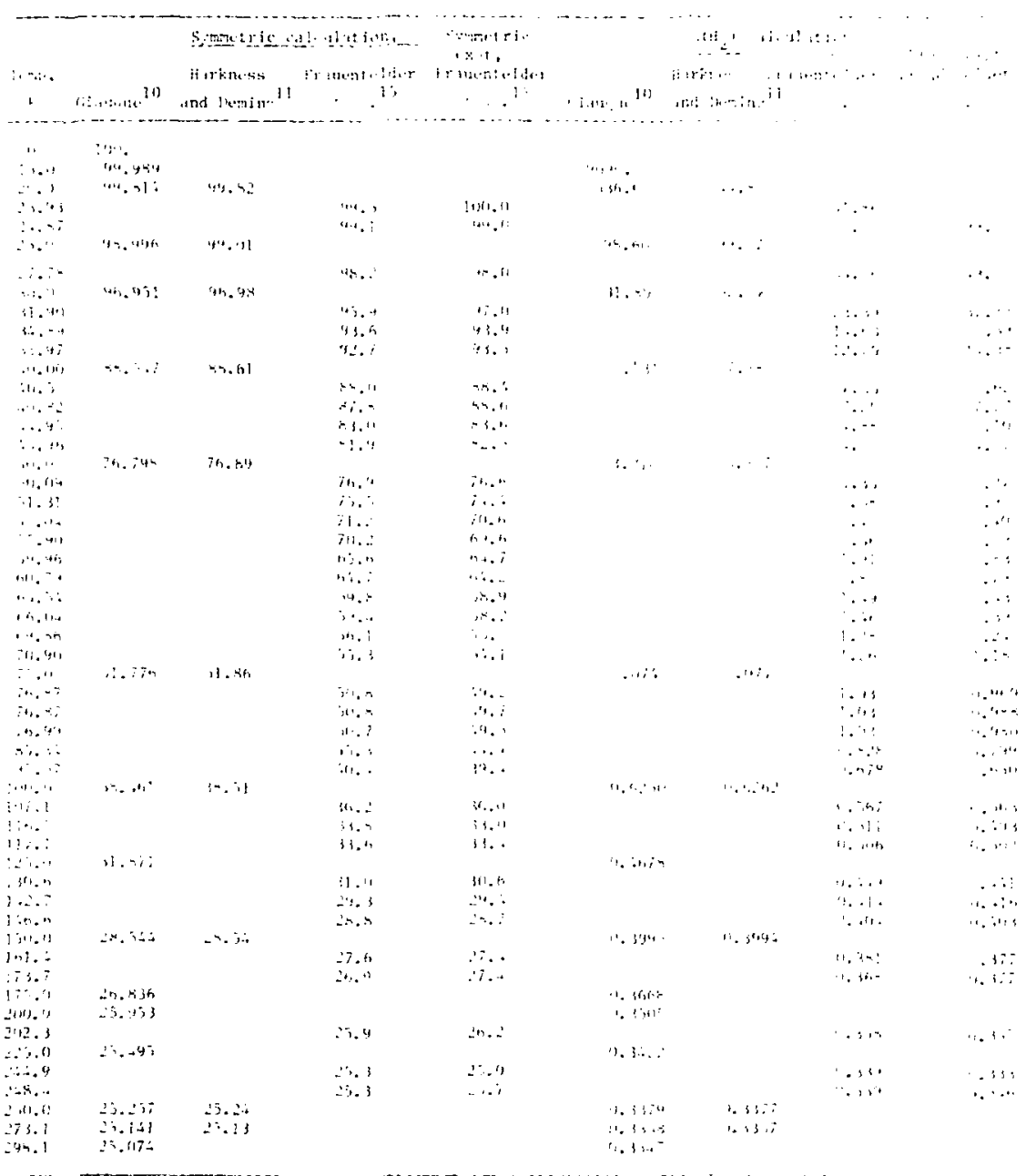


Table 3. Percentage symmetric forms and $R\left(D_{2}\right)$ values for deuterium.

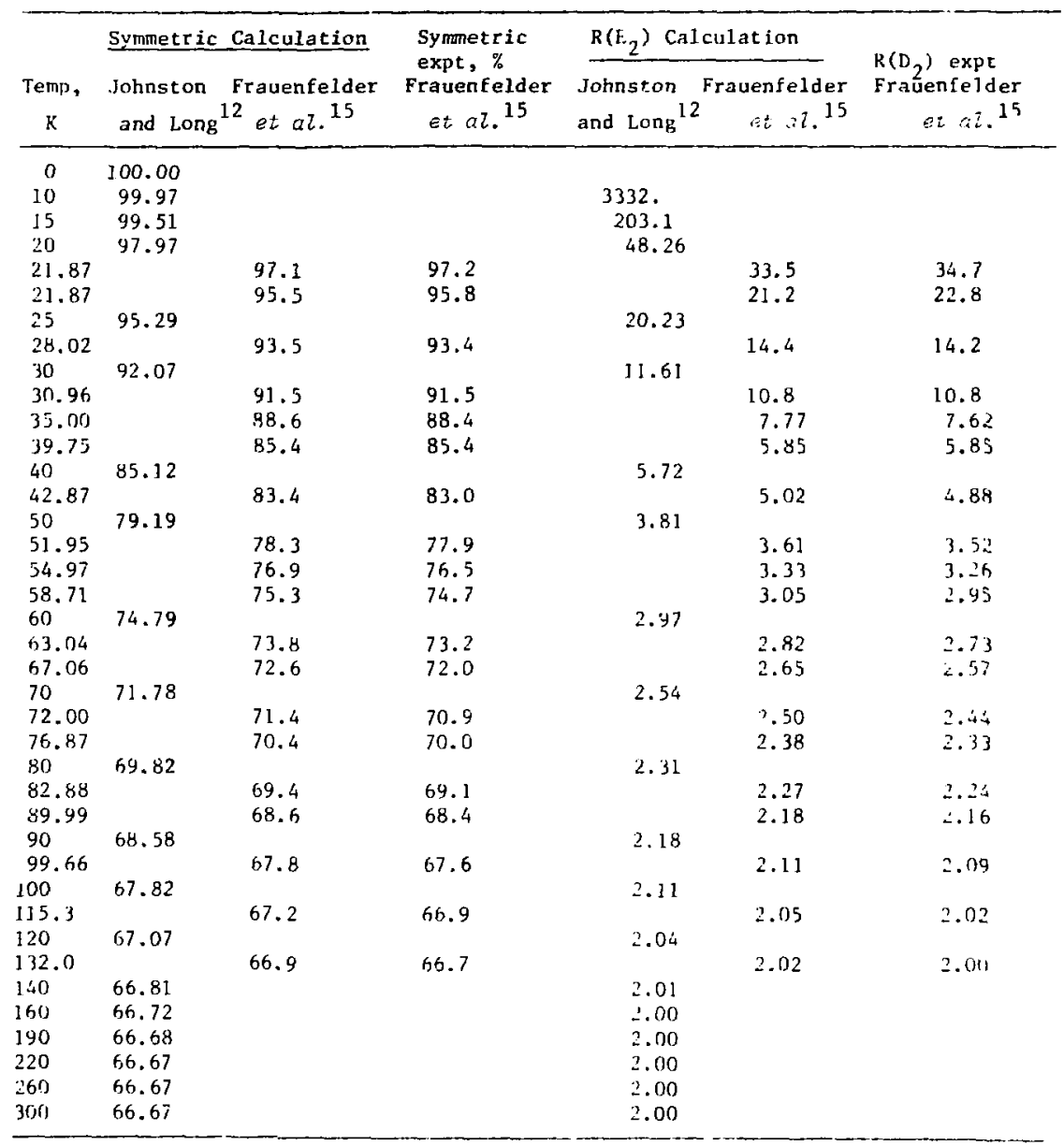


Table 4. Percentage symmetric form and $R\left(T_{2}\right)$ values for tritium.

\begin{tabular}{|c|c|c|c|c|c|c|}
\hline Temp, & Symmetri & $\begin{array}{l}\text { Calculintion } \\
\text { Frauenfelder }\end{array}$ & $\begin{array}{c}\text { Symmetric } \\
\text { expt, } \\
\text { Frauenfel der }\end{array}$ & & $\begin{array}{l}\mathrm{R}^{\left(\mathrm{T}_{2}\right)} \text { Calculation } \\
\text { Frauenteldur }\end{array}$ & $\begin{array}{c}\mathrm{k}(\mathrm{T}) \text { wht } \\
\text { fratuentelder }\end{array}$ \\
\hline$k$ & Jones ${ }^{13}$ & $\therefore: i{ }^{13}$ & $\therefore \quad 2: 13$ & Jones 3 & $\therefore: \therefore 3$ & \\
\hline 10 & 97.18 & & & 34.4 & & \\
\hline 13 & 83.57 & & & 5.09 & & \\
\hline 30 & 66.19 & & & 1.96 & & \\
\hline 20.85 & & 63.9 & 63.2 & & 1.77 & 1.73 \\
\hline 22.24 & & 59.7 & 57.2 & & 1.48 & 1.34 \\
\hline $24.1,6$ & & 55.0 & 53.1 & & 1.22 & 1.13 \\
\hline 25 & 52.55 & & & 1.11 & & \\
\hline 25.37 & & 52.0 & 49.3 & & 1.08 & 0.972 \\
\hline 27.04 & & $4 x .6$ & 43.9 & & 0.946 & 0.783 \\
\hline 28.65 & & 45.6 & 39.9 & & 0.838 & D. ristis \\
\hline 30 & $\therefore 3.31$ & & & 0.764 & & \\
\hline 30.79 & & 42.4 & 37.1 & & 11.736 & 1). 7911 \\
\hline 32.87 & & 39.7 & 35.6 & & 0.658 & 13.553 \\
\hline 34.73 & & 37.6 & 33.5 & & 0.503 & 10.501 .4 \\
\hline 35 & 37.22 & & & 0.593 & & \\
\hline 37.68 & & 35.0 & 33.6 & & 0.538 & $11.511 \mathrm{~h}$ \\
\hline$\therefore 0$ & 33.20 & & & $0 . .97$ & & \\
\hline 40.83 & & 32.8 & 32.0 & & 11.488 & 4.471 \\
\hline 43.71 & & 31.3 & 29.7 & & 19.456 & 0.422 \\
\hline$: 7.7 t_{3}$ & & 29.5 & 28.2 & & 0.418 & $i .393$ \\
\hline 50 & 28.73 & & & 0.403 & & \\
\hline 51.77 & & 28.2 & 28.4 & & 0). 393 & 01.397 \\
\hline 61.57 & & 26.6 & 25.0 & & $0.36 ?$ & 0.333 \\
\hline 64.53 & & 26.0 & 26.5 & & 0.351 & 0.361 \\
\hline 72.33 & & 25.6 & 26.8 & & 0.344 & 1). 366 \\
\hline 75 & 25.52 & & & 0.343 & & \\
\hline 76.88 & & 25.4 & 24.3 & & 1). 340 & 17.381 \\
\hline 100 & 25.07 & & & 0.335 & & \\
\hline 125 & 25.01 & & & 0.334 & & \\
\hline 150 & 25.00 & & & 0.333 & & \\
\hline 175 & 25.00 & & & 0.333 & & \\
\hline
\end{tabular}




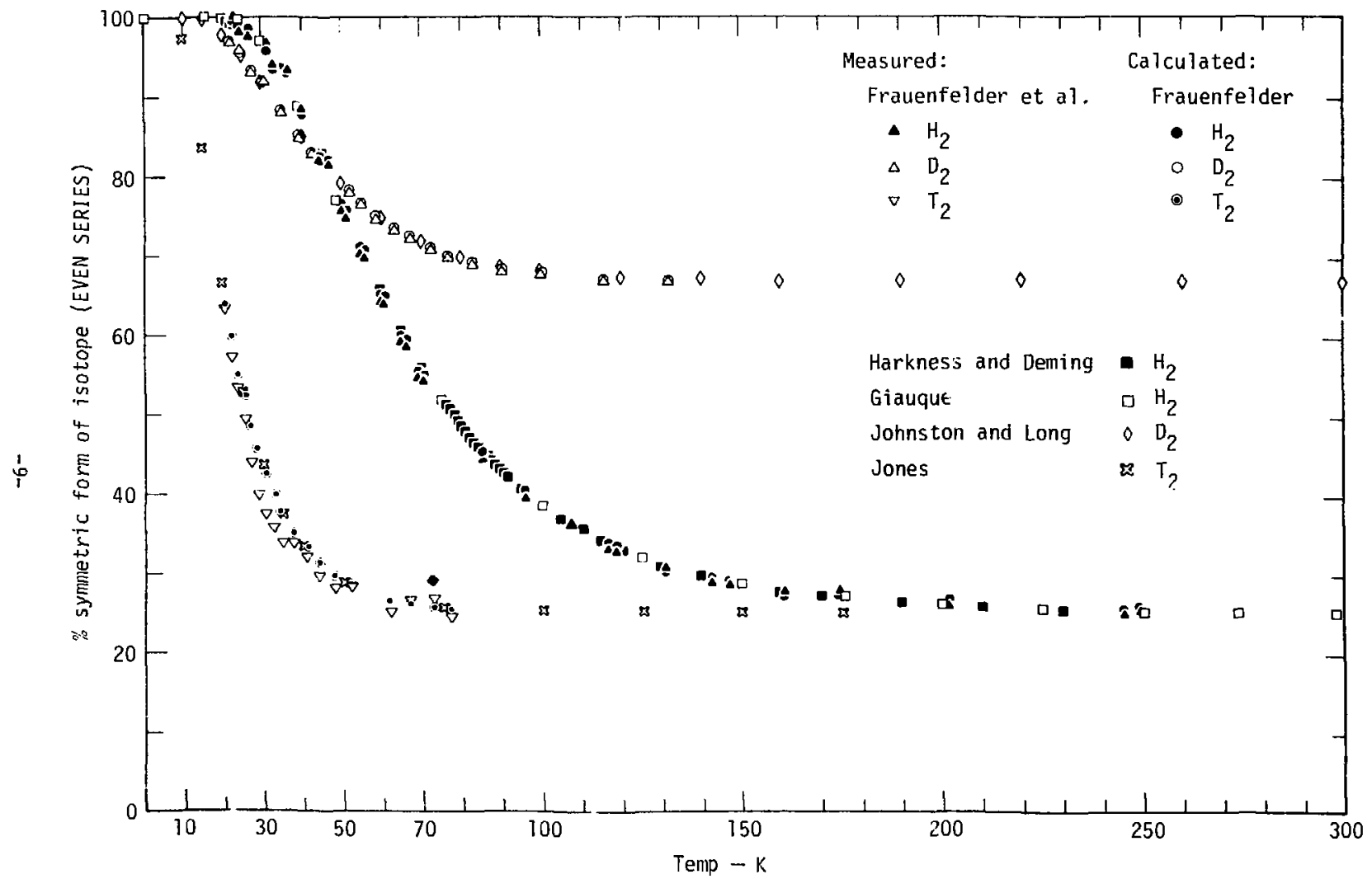

Fig. 1. Symmetric-antisymmetric equflibrium percentages of hydrogen isotopes as a function of temperature. 
species since they are based on more recent values of the rotational constants.

It should be emphasized that all of the preceding measurements and calculations are for the gas phase. We found no specific data on the symmetric-antisynuetric compositions in the hydrogen species in the con- densed phases. Welsh and his coworkers ${ }^{16}$ have pointed the way to such data, however, by their studies of quantum diffusion of orthohydrogen in solid para-hydrogen. Using their infrared technique, we should be able to study the orthopara transition in the liquid and soli.d phases.

\section{Rate of Radiation-Induced Symmetric-Antisymmetric Transition}

As we pointed out in the Introduction to the theory, the symmetricaztisymmetric transition in the hydroget. isctopes is not spontaneous; it recuires some sort of catalytic process. The transition induced by the ritium $\beta$-particle $\mathrm{e}^{17}$ is an example of the chemical mechanism. The requirement for this mechanism is some process that produces hydrogen at jms or 1ons. Unfortunately, the early and later workers disagree as co whether the mechanism is atomic or ionic. This disagreement cannot be resolved at this time since their data do not overlap, nor.do the later workers address the discrepancy. The early work was by Eyring, Hirschfelder, and Taylor ${ }^{18}$ who studled the symmetric-antisymmetric transition in hydrogen induced by $\alpha$-particles. They proposed that a free-hydrogen atom mechanism was more probable than an ionic one:

$$
\begin{aligned}
& \mathrm{H}_{2}+\alpha+2 \mathrm{H} \cdot+\gamma \\
& \mathrm{p}-\mathrm{H}_{2}+\mathrm{H} \cdot \pm \mathrm{O}-\mathrm{H}_{2}+\mathrm{H} \cdot .
\end{aligned}
$$

The d-particles cause dissociation into free-hydrogen atoms followed by a free atom and a bound atom interchanging, causing an ortho-para transition. The latter workers, Albers et al. ${ }^{14}$ in a tritium study and Conant et $a l^{19}$ in a study of gamma ray and neutron-induced symmetric-antisymmetric conversion in hydrogen, indicated that an ionmoleculc mcticiusism fit their experimental data better.

The suggested mechanism from Conant et al. ${ }^{19}$ follows:

$\mathrm{H}_{2}+\mathrm{v}($ or $\mathrm{n})$

$$
=\mathrm{H}_{2}^{+}+\mathrm{e}^{-} \text {chain initiation }
$$

$$
\mathrm{H}_{2}^{+}+\mathrm{H}_{2}=\mathrm{H}_{3}^{+}+\mathrm{H}
$$




$$
\begin{aligned}
& \mathrm{H}_{3}^{+}+\mathrm{H}_{2} \\
&=A_{3}^{+}+\mathrm{H}_{2} \text { chain propagation, }
\end{aligned}
$$

where the $\mathrm{H}_{2}$ molecule can be either a symmetric or antisymmetric hydrogen. The chain-terminating step requires a third body, R:

$$
\begin{aligned}
\mathrm{H}_{3}^{+}+\mathrm{e}^{-}+\mathrm{R} \\
\quad=\mathrm{H}_{2}+\mathrm{H}+\mathrm{R} \text { chain termination. }
\end{aligned}
$$

The physical mechanism, which is the one that predominates at low temperature, requires a collision with a paramagnetic molecule in the gas phase or on a surface. The conversion is caused by the influence of the inhomogeneous magnetic field upon the nuclear magnetic field of the hydrogen molecule. This can be mechanistically represented as

$$
p-\mathrm{H}_{2}+\mathrm{O} * \mathrm{o}-\mathrm{H}_{2}+\mathrm{O} *
$$

with an oxygen atom, $0 \cdot$, as the paramagnetic agent. In their review article, Schmauch and Singleton ${ }^{2}$ indicate that an effective low-temperature catalyst must have the following:

(1) a large physical adsorptive capacity for hydrogen, (2) a high concentration of the active catalyst specie, and (3) a high paramagnetic susceptibility. They developed a catalyst designated APACHI-1 that was more effective than those previously used. Other catalysts used by the workers cited in this review are hydrous ferric oxide gel, ${ }^{2}$ charcoal, 2,11 chromia on alumina, ${ }^{3}$ and cerium oxide. $^{15}$

We did not find in the literature what we considered to be a complete kinetic study of the radiation-induced symmetric-antisymetric conversion of the hydrogens. Fessler and BIue $17(\mathrm{a})$ in a study of the conversion in liquid hydrogen caused by a fast neutron irradiation indicated that their data could not be fit by the assumption of a first-order reaction. The mechanism that seemed to $f$ it their data was a two-step process: step one with a lifetime of $8.1 \mathrm{~min}$, which was inactive in causing conversion; and step two with a liferime of $5.7 \mathrm{~min}$, which caused the conversion. No rate equation or rate constants were given. This mechanism is consistent with that described by conant et at. ${ }^{19}$ which we illustrated by Eqs. $10-13$ wherein the chain initiation step [Eq. (10)] would be the slow or rate determining step. Nelms and Carter ${ }^{17 \mathrm{~b}}$ also studied the conversion in hydrogen using both gamma and neutron radiation. They give the rate of increase for orthohydrogen from irradiated para-hydrogen as

$$
\begin{aligned}
\frac{d\left[\mathrm{o}-\mathrm{H}_{2}\right]}{d t}= & \frac{3}{4} k[\mathrm{H} \cdot]\left[\mathrm{p}-\mathrm{H}_{2}\right] \\
& -\frac{1}{4} \mathrm{k}[\mathrm{H} \cdot]\left[\mathrm{O}-\mathrm{H}_{2}\right],
\end{aligned}
$$


where $k$ is the rate constant for hydrcgen exchange. The brackets denote concentrations, and $H^{*}$ stands for hydrogen atoms. The first term represents the forward conversion and the second term the back conversion to para-hydrogen. The value of $k$ used was $3.6 \times 10^{8} \mathrm{~cm}^{3} /$ mole sec at $300 \mathrm{~K}$. This equation is not useful to us because it depends on the hydrogen atom conceltration, which is difficult to measure.

Other workers have given kinetic data in terms of conversion half times without specifying mechanisms or giving a rate equation. Jones ${ }^{13}$ has estimated the half time of B-catalyzed ortho-para transition in tritium gas to be a few days, presumably at room temperatures. Albers et i.. ${ }^{14} \mathrm{re}-$ ported the conversion half time for tritium on coconut charcoal as $0.92 \mathrm{~min}$ at $27.2 \mathrm{~K}$ and $1.0 \mathrm{~min}$ at $77.4 \mathrm{~K}$; ihe conversion half time for deuterium on the same catalyst was $19 \mathrm{~min}$ at $27.2 \mathrm{~K}$. The tritium conversion in the solid at $4.2 \mathrm{~K}$ had $a$ half time of 17 min. Conant es $:^{19}$ in a study of $\mathrm{p}-\mathrm{H}_{2}$ conversion induced by gamma and neutron radiation silw appreciable conversion at $300 \mathrm{~K}$ and $395 \mathrm{k}$ but very little at $77 \mathrm{~K}$. Albers et al. ${ }^{14}$ also noted very slow conversion in tritium yas at $27.2 \mathrm{~K}$.

\section{Self-Induced Symmetric-Antisymmetric Conversion Kinetics}

In the gas phase, the self-induced symmetric-antisymetric conversion rate of the hydrogen isotopes is very slow. On the other hand, the selfinduced conversion in the liquid and solid phases may be appreciable. In liquid and solid tritium, we would expect that the self-induced conversion would be overshadowed by the radiation-induced process.

Much of the data on the selfinduced ortho-para conversion in 11quid hydrogen and deuterium dates from ear $1 \mathrm{y}$ measurements in the $1930^{\prime} \mathrm{s}$.
Woolley, Scott, and Brickwedde ${ }^{20}$ have reviewed this early wrok; the discussion that follows is based on their paper. The self-conversion depends upon a magnetic interaction on a molecular scale, and, since symmetric hydrogen has no nuclear magnetic moment (spin opposed), the selfconversion of symmetric-antisymmetric mixtures depends only on the interaction of untisymetric molecules with each other and with symetric molecules. The symmetric-symmetric interaction does not cause conversion. 
The rate equation is therefore written

$$
\begin{aligned}
& -\frac{\mathrm{d}\left[\mathrm{asym}-\mathrm{H}_{2}\right]}{\mathrm{dt}}=k_{1}\left[\text { asym- } \mathrm{H}_{2}\right]^{2} \\
& -k_{2}\left[\text { asym }-\mathrm{H}_{2}\right\}\left[\text { sym- } \mathrm{H}_{2}\right] .
\end{aligned}
$$

The rate constant $k_{2}$ is much smaller than $k_{1}$ and the second term is omitted by the earlier workers. ${ }^{21}$ For liquid hydrogen, the second-order rate constant $k_{1}$ is equal to 0.0114 per hour when roncentrations are axpressed ats mole Cractions. The value of $\mathrm{k}_{1}$ for sulid $\mathrm{H}_{2}$, 0.019 per hosur, is larger than that for liquid $\mathrm{H}_{2}$ but decreases with time due to inmobility of the molecules in the solid. The initial value or $k_{1}$ is restored by melting and rreezing.

The self conversion of ortho and para $\mathrm{D}_{2}$ in the liquid phase proceeds at a much slower rate than the $\mathrm{H}_{2}$ rate. This is due to the much smaller mognetic moment of the deuteron as compared wit': that of the protun. Brickwedde, Scott, and Ta: $10 \mathrm{r}^{21}$ showed by means of a theoretical analysis that

$$
\frac{\mathrm{d}\left[\mathrm{asym}-\mathrm{H}_{2}\right]}{\mathrm{dt}}, \frac{\mathrm{d}\left[\mathrm{dsym-b_{2 } ]}\right.}{\mathrm{dt}}=340 .
$$

Their analvsis also showed that

$$
-\frac{d\left[\operatorname{asym}-D_{2}\right]}{d t}=k_{n}\left[\operatorname{asym}-D_{2}\right]
$$

instead of the square of the concentration as it is for the curresponding change in hydrogen.

A number of cajculations and experiments uiving the rate of the selfinduced symmetric-antisymetric conversion in liquid and solicl hydrogen have been reported. These results have bean compared for solid hydrogen by Schmidt ${ }^{22}$ and for liquid hydrogen by Milenko and Sibileva ${ }^{23}$. For hydrohen, all the values ire essentially in agreement with those reported for k.l. (16), $k_{1}=0.0114$ per hour for liquid hudrogen and 0.019 per hour for solis! lyedrogen. Schmidt ${ }^{22}$ discusses the cefert of molar diffusion and clectric quadruple-quadruple interaction on the conversion rato in solid hydrogen at tomperatires below $4.2 \mathrm{~K}$ and at times longer than 300 hours. Lnder these cunditions, the simple bimolecular model does not hold, and an increase of the conversion rate with decroasing antisymmetric hydrogen is seen.

The theoretical calculations of the rate of symetric-antisymmetric conversion in sillid deuterium have been compared with thc experimental rate by Grenier and white. ${ }^{24}$ They give a rate equation analogous to $\mathrm{Fq} \cdot(16)$ :

$$
\begin{aligned}
& -\frac{d\left[a s y-D_{2}\right]}{d t}=k_{1}\left[\operatorname{ascm}-D_{2}\right]^{2} \\
& +k_{2}\left[a s y m-D_{2}\right]\left[\text { symm } D_{2}\right],
\end{aligned}
$$


with $k_{1}=1.27 \times 10^{-3} h^{-1}$ and $k_{2}$ $=1.78 \times 10^{-3} h^{-1}$. The agreement be. tween their data and experiment was considered to be good taking account of the experimental error. Milenko and Sibileva ${ }^{23}$ report an analysis in disagreement with that of cirenier and White. They report an extensive experimental study of the conversion rates in both liqquid and solid hydrogen and 1 iquid and solid deuterium. As mentioned earlier, their hydrogen data agrees well with that of previous workers. They show that their deuterium data can be $\mathrm{fit}$ by Eq. (18) rather than Eq. (19). They report values of $k_{D}=3.3 \pm 0.1 \times 10^{-4} h^{-1}$ for liquid $\mathrm{D}_{2}$ at $20.4 \mathrm{~K}$; and $\mathrm{k}_{\mathrm{D}}=5.3$ $\pm 0.3 \times 10^{-4} \mathrm{~h}^{-1}$ at $4.2 \mathrm{~K}$.

Their data in solid deuterium disagrees with that of the theory and with Grenier and wite. ${ }^{24}$ We also found some dati for 1 iquid and solid deuterium in Ref. 25, which likewise disagrees with Milenko and Sybeleva. 23 Because of the precision of their experimental data and their straishtforward analysis, we recommend the values of $k_{23}$ given by Milenko and Sibileva.

\section{Summary and Conclusions}

For our purposes, it is of interest to compare the rates of the various mechanisms of symmetric-antisymmetric conversions as a function of isotopic hydrogen and phase. In Table 5, we list the half times of some conversion rezctions under different conditions. Some of the half times were taken directly from the 1iterature, such as those from Refs. 13 and 14. Others, such as those from Refs. 17b, 20, and 23, were calculated from rate corstants or taken from graphs. No extensive efforts were made to find rate constants for different processes using various catalysts, as pointed out before. The catalytic conversion for $D_{2}$ and $T_{2}$ from Ref. 14 were in- cluded for comparison with the author's other data. The transition half times are also plotted as a function of $\log T$ in Fis. 2. The data Erom Table 5 and Fig. 2 indicate that in general the catalytic process even in the gas phase is the most rapid, although the combination of the tritium B-ray and catalyst rives the fastest rate listed in the table. Also the radiation-induced conversion (1iquid $\mathrm{H}_{2}$ at $20 \mathrm{~K}$, gas $\mathrm{T}_{2}$ at $300 \mathrm{~K}$, and solid $T_{2}$ at $4.2 \mathrm{~K}$ ) is more rapid than the self-induced conversion in the liquid or solid state.

One of our proposed measurements is the equilibrium constant for the reaction $\mathrm{D}_{2}+\mathrm{T}_{2}=2 \mathrm{DT}$ in the gas and 


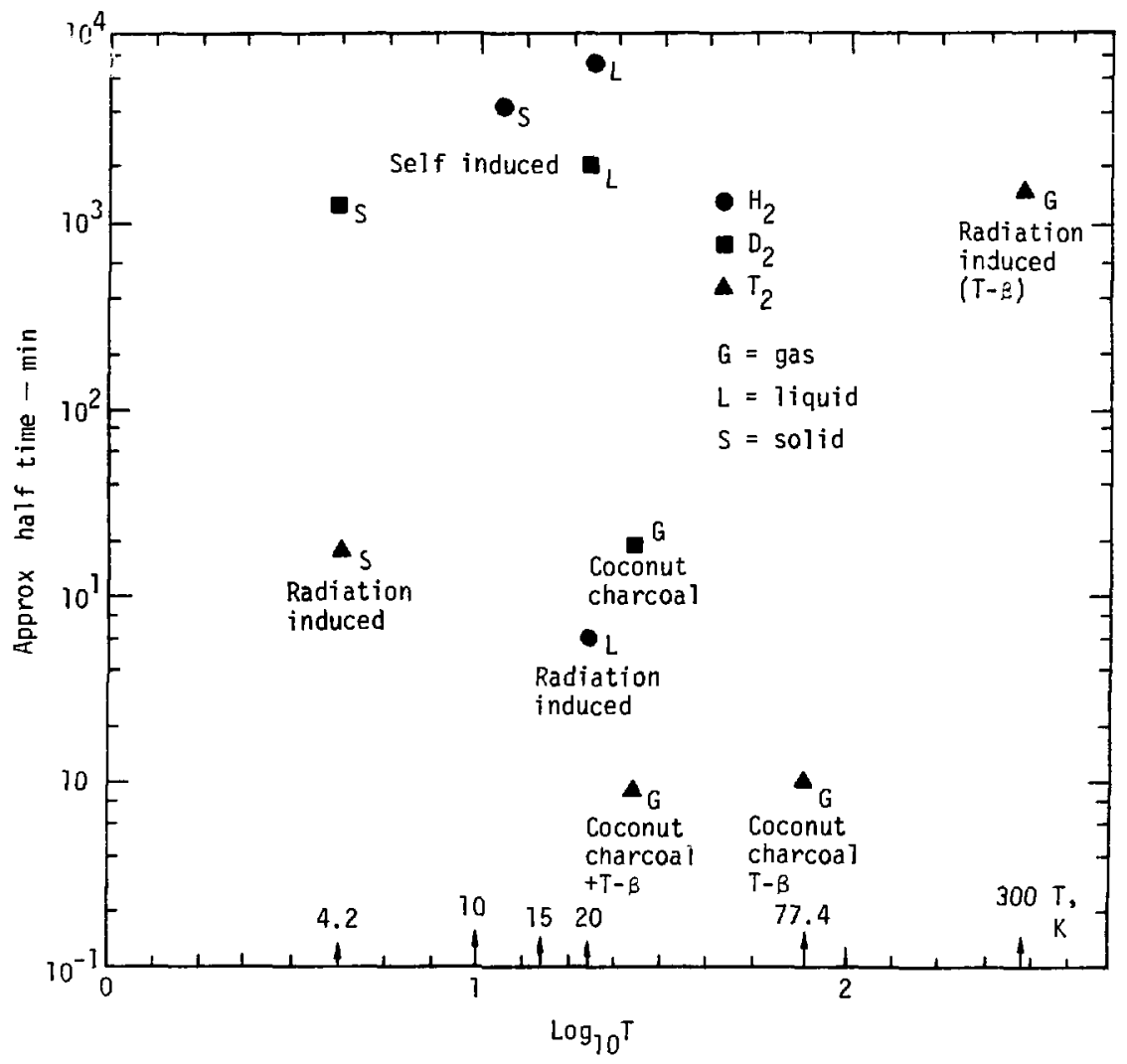

Fig. 2. Plot of symmetric-antisymmetric half times of $H_{2}, D_{2}$, and $T_{2}$ as a function of $\log _{10} \mathrm{~T}$. 
Table 5. Comparison of symetric-intisimetric ionversion rates for H2, $\mathrm{H}_{2}$, and $\mathrm{T} 2$, fur some catilyzed (C), radiation-juduced (RI), and self-induced (SJ) procesties.

Rates are expressed as hal times in minutes and temperatures in kelvins.

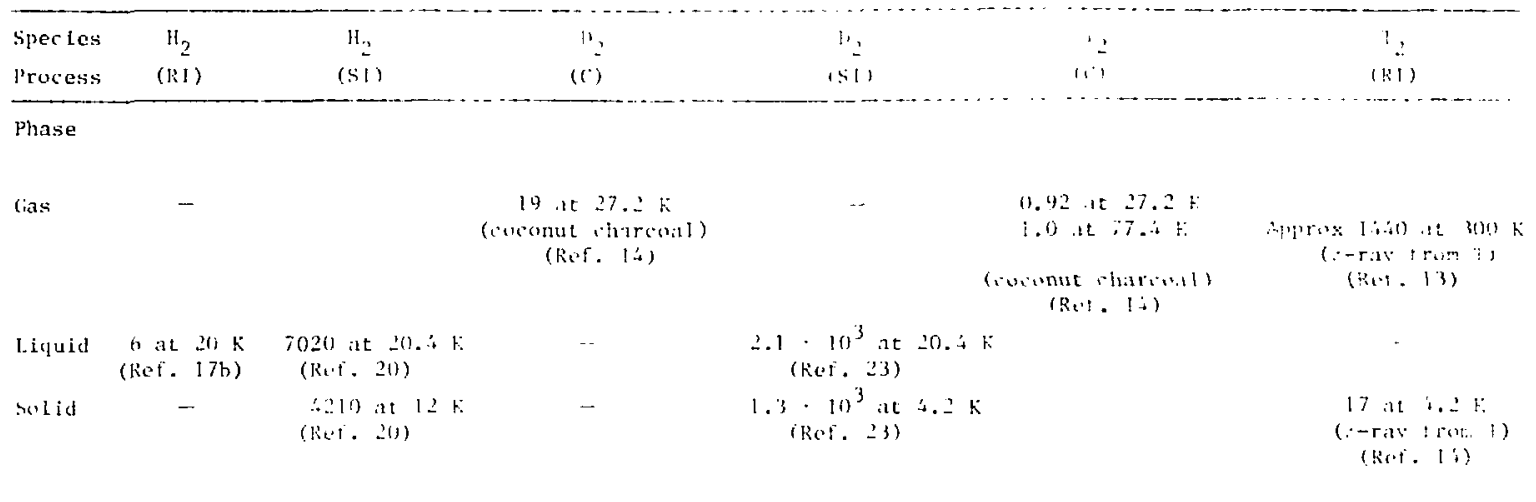


1iquid phases. If we hope to compare the experimental results with our calculations from spectroscopic data, ${ }^{7}$ we need to know the symmetric-antisymmetric states of the tritium and deuterium. The radiation-induced conversion in 11 quid hydrogen from Ref. $17 \mathrm{~b}$ indicates that the radiation-induced rate in liquid $\mathrm{D}_{2}$ and $\mathrm{T}_{2}$ may be fairly rapidon the order of a few minutes. In any case, we plan to measure $\mathrm{R}\left(\mathrm{T}_{2}\right)$ and $R\left(D_{2}\right)$ and the conversion rate in a liquid-phase mixture of $\mathrm{D}_{2}, \mathrm{DT}$, and $\mathrm{T}_{2}$ using infrared spectroscopy.

\section{Acknowledgments}

We thank Robert Epple and others of the bivision of Physical Research, Finergy Research and Development Administration Washington, D. C., for their support of basic DT studies at cryugenic temperatures. We also thank Clark Souers who had the original idea for this cryogenic program and under whose direction it proceeds. 


\section{Notes and References}

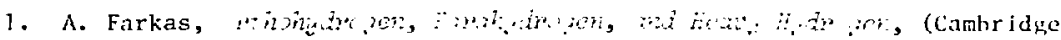
Press, Cambridge, England (1935).

2. G. 1.. Schmauch and A. H. Singleton, "Technical dispects of ortho-Para Hydrogen Conversion," End. Anp. Cherm. 56, 20-31 (1964).

3. B. 3. Scalapino and K. G. Pelzinger, "Para-to Ortho-Hydrogen conversion

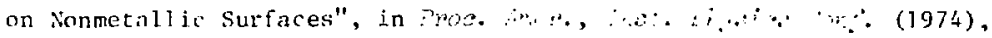
vo1. 18, nt.1, pp. 8-18.

4. Ref. 1, p.1.

5. For a brief doscription of the underlying theory see W. J. Moore, : $y_{0}:$ sal Pemie:? (Prontice Hall, Inc., Engleword Cliffs, N. I. 1962) 3rd Fd., pp 639-41. For more rigorous mathematical treatment see references

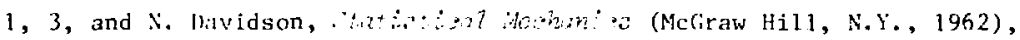
pp. 130-8.

6. The partition function forms the 1 ink between macroscopic thermodynamic functions and the energy levels of indjuidual molecules. It is defined as $Z=\sum_{j} k_{j} e^{-\varepsilon}{ }_{i} / k T$ (see Moore, $p .622$ ) where $g_{j}$ is the statistical weight of the $j$ th energy level $\varepsilon_{j}, k$ is Boltzmann's constant, and $t$ is the absolute temperature.

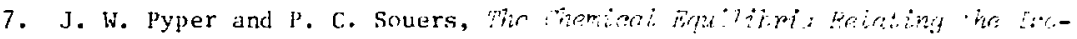

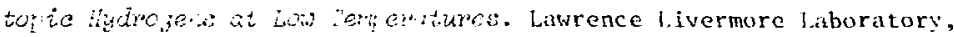
Rept. UCRL-52104 (1976), p.7.

8. P. C. Souers, R. G. Hickman, W. Z. Wade, and R. T. Tsugawa, Fizimit;

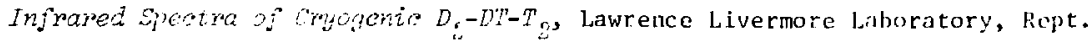
UCRL-51674 (1975), pp. 3-4.

9. Recommended rotational constants $B_{e}$, are given in Ref. $7, p p .23$.

10. W. F. Giauque, "The Entropy of Hydrogen and the Third Law of Thermodynamics, the Free Energy and Dissociation of Hydrogen," $\therefore$. Am. Chem. soc. 52, 4816-31 (1930).

11. R. W. Harkness and W. E. Deming, "The Equilibrium of Pard and Ortho Hydrogen," d. An. Shem. Soc. 54, 2850-2 (1932). 
12. H. L. Juhnston and F. A. Long, "Heat Capacity Curves of the Simpler Gases. VI Rotationa] Heat Capacity Curves of Molecular jeuterium and of Deuterium Hydride. The Fquilibrium Between the Ortho and Para Forms of Deuterium. Free Energy, Total Energy, Fntropy, Heat Capacity and Dissociation of $\mathrm{H}^{2} \mathrm{H}^{2}$ and of $\mathrm{H}^{1} \mathrm{H}^{2}$, to $3000^{\circ} \mathrm{K}, " \therefore$ Crifr. Phis. 2, 389-395 (1934).

13. W. M. Jones, "Thermodynamic Functions for Tritium and Tritium Hydride. The Equilibrium of Tritium and Hydrogen with Tritium Hydride. The Diesociation of Tritium and Tritium Hydride," $\therefore$ Cherr. Phas. 16, 1077-81 (1948).

14. E. W. Mlbers, P. Harteck, and R. R. Reeves, "Ortho and Para-tritium," 2 . ilatuforscho. 18A, 197-202 (1963); E. W. Albers, P. llarteck, and R. R. Reeves, "Ortho- and Paratritium," $\therefore$ Am. Chem. Boc. 86, 204-209 (1964).

15. R. Frauenfelder, F. Heinrich, and J. B. 01in, "The Ortho-Para Equilibriuta of $\mathrm{H}_{2}, \mathrm{D}_{2}$, and $\mathrm{T}_{2}$," Helv. ings. Act: $\underline{38}, 279-298$ (1965).

16. S. A. Boggs, M. J. Clouter, S. H. L. Welsh, "The Fundamental Infrared Absorption Band of Ortho-linriched Solid Hydrogen," Can. el. Thir. 50, 2063-2073 (1972). S. A. Boggs and H. I. Welsh, "An Infrared Spectroscopic Study of Quantum Diffusion in Snlid Hydrogen," im. A. Phy. 51, 1910-1914 (1973). B. J. Roffey, S. A. Bogrs, and H. I.. Welsh, "Infrared Studies of Quanturn Diffusion in Solid Hydrogen," "ki. $\therefore$ :his. 52, 2451-2453 (1974).

17. For evidence that radiation induces the ortho-para transition see a) T.E. fessier and J. W. Blue, "Radiation Induced Conversion of Liquid Hydrogen," injs. Rev. Lett. 14, 811-2 (1965). b) 1. W. Nelms and H. G. Carter, "XERVA Irradiation Program: Ci'k Test 21, vol 2., Nuclear Radiation - Induced Conversion of Para Hydrogen to Ortho Hydrogen," $U$. S. At. Enerky Comm. 1968, FZK-351-2, pp. 150.

18. H. Eyring, J. O. Hirschfelder, and H. S. Taylor, "The Theoretical Treatment of Chemical Reactions Produced by Ionization Processes, Part I. The Orthompara Hydrogen Conversion by Alpha Particles," $\therefore$, ingem. Fils. 4 , $479-491(1936)$.

19. J. W. Conant, F. I. Edesky, J. F. Huston, and F. V. Thome, "The Conversiun of Para to Orthohydrogen in a Gamma-ray and Noutron Radiation Field," $\because \because \ldots 15,12-16(1975)$. 
20. H. W. Woolley, R. B. Scott, and F. G. Brickwedde, "Compilation of Thurmal Properties of Hydrogen in 1 ts Various Isotopic and ortho-Para :udifications," $t$. Ges. Natr. Bur. Etand. 41, 379-475 (1948).

21. F. W. Brickwedde, R. B. Scott, and H. S. Taylor, "The Difference in Vapor Pressures of Ortho and Para Deuterium," e. Chem. Phys. 3, 653-660 (1935).

22. F. Schmidt, "Diffusion and Ortho-Para Conversion in Solid Hydrogen," D7i;s. Fev. 10B, 4480-4 (1974).

23. Yu. Ya. Milenko and R. M. Sibileva, "Natural Ortho-Para Conversion in $\|_{2}$ and $\mathrm{D}_{2}$ in the Liquid and Solid Phase," UR. Fiz. Zh. 19, 2008-2014 (1974) [UCRL translation 11229 (March 1977)].

24. G. Grenier and D. White, "Heat Capacities of Solid Deuterium (33.1 $\%$ 87.2\% Para) from $1.5^{\circ} \mathrm{K}$ to the Triple Points. Heat of Fusion and Heat Capacity of Liquid," e. Chem. Dings. 40, 3015 (1964).

25. Woolley and Brickwedde as quoted in H. M. Roder, G. E. Child, R. I. McCarty, and P. E. Angerhofer, "Survey of the Properties of the Hydrogen

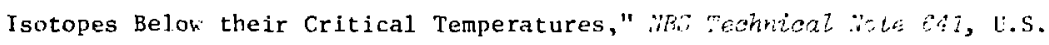
Dept. of Commerce, August 1973, 0.67. 